The rude pictographs or petroglyphs found in the island are equally remarkable. Some of the best specimens are engraved on boulders in rivers or in their vicinity, thus possibly indicating their use in some mimetic rain ceremony. Others, drawn with less care, differing from the river sculptures in size, shape, and apparently in significance, are inscribed in the caves so common in the calcareous rocks of the island. They represent in some cases a head furnished with horns, human faces, and rude representations analogous in type to the "three-pointed" images, with circles, spirals, and other symbols. Our knowledge of the aboriginal cults is at present too scanty for any attempt to explain their significance. That they represent objects of religious worship seems fairly certain.

Porto Rico is thus a most promising field for archæological investigation. The report of Dr. Fewkes suggests many interesting problems. It is well written, and, like other publications in the same series, is admirably illustrated.

Another article by the same writer describes a tour of exploration in eastern Mexico, undertaken with the object of ascertaining the relationship between the mound builders of the lower Mississippi and the people of the Mexican coast known as Totonac and Huaxtec. The Totonac metropolis, Cempoalan, was for the first time examined. From this investigation it seems probable that the mound builders of the southern States were more closely connected with the races of eastern Mexico than with those of the arid region of the south-west or even with the plateau tribes of eastern Mexico.

The third part of the thirteenth volume of the Journal of the Academy of Natural Sciences, Philadelphia, is devoted to a fresh exploration of Moundville, Alabama, and sites on the Crystal, Chattahoochee, and Lower Flint Rivers, and the Ten Thousand Islands of Florida, by Mr. C. B. Moore. The appearance of the Swastika symbol and other objects discovered at Moundville seems to indicate that this was an important religious centre, specially devoted to the worship of the sun, conducted in temples by an order of priests, who kept the sacred fire continually burning as an emblem of the luminary. The discovery at the Crystal River of an ear-ornament overlaid or covered with meteoric iron is an interesting proof of the skill of this race in metallurgy, and it seems to connect the races of Florida, who buried their dead in mounds, with the people of the Ohio valley region. This report also is provided with excellent illustrations of the remarkable series of finds which were secured by $\mathrm{Mr}$. Moore's expedition.

\section{THE NITROGEN PROBLEM IN AGRICUL- TURE.}

FOR many years what is known in agriculture as the nitrogen problem has received considerable attention both from men of science and from practical men. It has two aspects. Few soils contain nitrogen compounds in sufficient quantity for the needs of non-leguminous crops, and the application of nitrogenous manures is one of the commonest, as well as one of the more costly, operations of modern agriculture. On the other hand, leguminous crops not only need no nitrogenous manure for themselves, but actually increase the store of nitrogen compounds in the soil, and dispense with the necessity of adding more for the succeeding crop. The problem would obviously vanish if leguminous crops could be grown every other year, but unfortunately they are liable to " sickness," and can only be grown once in four or even six rears. Even as it is, however, any method that increases the nitrogen-fixing power of a leguminous crop is a welcome addition to the resources of a farmer.

In 1886 Hellriegel and Wilfarth showed that nitrogenfixation is the work of certain micro-organisms associated with the leguminosæ. It has since been shown that they can grow apart from the plant, and can be inoculated into soils, and also that an increased crop may follow such inoculation.

On three occasions cultures of these organisms have I "Seed and Soil Inoculation for I eguminous Crops." By Prof. W. B. Bottomley. (Landon : Country Life Office.) been widely distributed among farmers. In 1896 Nobbe sent out "nitragin"; in 1903 Moore's cultures were issued in America; and now we have Prof. Bottomley's cultures. Each time very great and widespread interest has been aroused, the matter has been discussed at length in the daily Press, and has even on occasion formed the subject of questions in the House of Commons. The subject appeals to almost everyone. Few scientific problems are more interesting than the wholly unparalleled synthesis of complex organic compounds from free nitrogen and other simple bodies effected by these micro-organisms at the low temperatures of the soil. The practical man sees in inoculation the possibility of increased leguminous crops and of less expenditure on nitrogenous manure for his other crops. The man in the street, who has always been ready to take an interest in nitrogen since Sir William Crookes's British Association address at Bristol in 1898 , sees the threatened nitrogen famine averted and his food supply rendered secure for a long time to come.

Inoculation has proved very successful on virgin soils, or in dealing with new leguminous crops, but there is little or no evidence that it is effective when the soil is already in cultivation and the crop no longer new. Nobbe's cultures failed, and Moore's cultures were not particularly successful when applied in ordinary farm practice. Certain other less boomed cultures, e.g. Hiltner's, have done better, and have sometimes given 20 per cent. or 30 per cent. increases in crop. Prof. Bottomley tested his culture by distributing more than a thousand specimens; 80 per cent. of the reports received (unfortunately we are not told the actual number) showed an increase in crop. The pamphlet before us consists largely of extracts from these reports.

Experiments of this nature are very difficult to carry out. Great care is necessary in selecting the ground, proper control plots are needed, and the experiment must be continued for several years without essential modification. Under favourable conditions, the error of a field experiment lasting many years may be as low as 5 per cent, but for shorter periods it is much higher. We cannot find any evidence that these facts have been taken into account; on the contrary, most of the trials have obviously been made by novices. Only in a few cases have any weights been taken, and the results have usually been guessed. Here is an "experiment" with peas :-

"I planted the inoculated peas on land that had not been manured for many years, and had a crop of peas quite equal to those grown by a friend on manured soil" (p. 24).

Another:- "Gradus' without inoculation, a fair crop but they were soon over."

" 'Sutton's A I' inoculated, heavy crop, with abundance of well-filled pods" (p. $2 \mathrm{x}$ ).

Again :- "First sown peas, inoculated, a fine crop. .. Second sowing, uninoculated, results very poor. . . The ground on which first crop was sown had had no peas on it for several years, whereas the ground on which second crop was sown had had peas grown on it in the previous year" (p. I7)

It is scarcely necesary to say that statements of this kind are of no scientific value.

Fifty-two reports are quoted; fifteen must certainly be rejected, eighteen give no figures, thirteen give estimated figures, and six give weights. Confining our attention to the nineteen cases where figures are given, we find that in four the increased yield is 20 per cent. or less; this cannot be much greater than the magnitude of the experimental error. In nine cases the estimated increase is 30 per cent. to $5^{\circ}$ per cent., and in five cases more than 50 per cent. A detailed discussion is obviously impossible we can only point out that a few experiments properly made on sound lines would have been very much better than all these testimonials. So far as they prove anything at all however, they go to show that the author has like Hiltner in Germany, Moore in the United States, and Golding here, obtained cultures which may in suitable cases increase the yield of leguminous crops, and the increase seems to be estimated in the majority of cases at about 30 per cent. to 50 per cent.

Now if it this turns out to be correct it will be a very useful result, but in ordinary farming it can only be 
looked for once every fourth or sixth year, tor it is not claimed that inoculation cures "sickness" and increases the frequency with which leguminous crops can be grown. Even a 50 per cent. increase in crop, useful though it would be, would in these circumstances hardly effect any particular revolution in agricultural practice. We are therefore unable to follow the author when he remarks:- "For a few thousand pounds the 2 I million acres of poor barren land in this country could be made productive and rendered capable of finding work for and supporting such a population that both the food problem and the unemployed problem would be easy of solution.... Waste land recclaimed and made fertile for $6 d$. an acre !..." It would have been better if the author had induced an agricultural friend to revise this estimate. We are told on pp. 8 and ro that inoculation will be a failure when the soil is too acid and in need of lime, when it is deficient in phosphates and potash, when the physical conditions of the soil are unfavourable, or when drainage is needed. Barren land in England commonly suffers from several or all of these defects. How far would sixpence an acre go in putting them right?

At a time when the farmer needs, and is willing to accept, all the assistance the scientific investigator can give him, the fact that an enthusiastic worker like Prof. Bottomley has directed $\mathrm{h}$ is attention to agricultural botany is a matter for congratulation, and we can only regret that in this, his first appeal to the practical man, his enthusiasm should have outrun his judgment. However, although we must regard the present production as unsatisfactory, we still look forward to sound work from the author on this subject, and we wish him success in his work on the numerous and difficult problems connected with soil inoculation.

E. J. R.

\section{MATHEMATICAL EDUCATION AND RESEARCH.}

THE annual meeting of the Mathematical Association was held at King's College, London, on Saturday, January 25. The proceedings bear abundant testimony to the great changes which are taking place in the methods of teaching mathematics, and show that these changes are not confined to the subject of elementary geometry. Mr. W. J. Dobbs showed what useful work could be done by means of simple home-made apparatus in the teaching of mechanics, his apparatus consisting merely of spiral springs with cardboard scales attached for illustrating applications of the parallelogram law, and suspended sticks for illustrating the principle of the lever and the balance. $\mathrm{He}$ further showed how the solution of problems on accelerated motion could be greatly simplified by the application of direct methods not involving such restrictions as to units as are necessary in working with "poundals" or "slugs." Mr. C. O. Tuckey made a distinct step in advance in his suggestions as to the methods of introducing the properties of convergent series to students who require these series principally in the study of the calculus, and it is interesting to compare his views with those which prevailed twenty or thirty years ago, when the calculus was regarded as something sacred which should not be handled by students until they had passed through a lengthy period of probation in working with algebraic series. Mr. F. J. W. Whipple's lantern-slides, showing how the convergency of certain trigonometric series could be illustrated by diagrams drawn by mere beginners, were a revelation to those who had approached the subject by the study of pages of long formulæ. Mr. W. E. Bryan suggested a very original way of introducing similar figures in geometry, a method which, however, may well form a basis of further discussion and criticism. An apparatus for drawing rectangular hyperbolas was shown by Mr. H. L. Trachtenberg.

In his presidential address Prof. G. H. Bryan, F.R.S., dealt with the uses of mathematics and the training of mathematical teachers. It was necessary that the public should be made aware of the important part which higher mathematical research had played, and was destined to play, in practical applications on which the prosperity of a nation depended. As an instance, Prof. Bryan referred to the seemingly unpractical and uninteresting study of the properties of imaginary quantities, without which modern applications of electricity to purposes of commerce, including wireless telegraphy, could never have reached their present developments. In order to overcome the existing lack of public interest in mathematical matters it was important that the university training of every mathematical teacher should afford him some insight into the research aspect of some one branch of the subject, and the experiments that had already been made in this direction in the university colleges of Wales showed that this ideal was quite capable of attainment. Turning to the teaching of mathematics in elementary schools, Prof. Bryan expressed the opinion that the children of the working man should learn to measure and calculate correctly in order that they might become more efficient and improve their positions in the labour market. If their teaching was conducted in such a way as merely to stimulate in them a spirit of luxury and discontent as distinct from a desire for self-improvement, the working classes had quite as much cause for complaint as the tax-payers. But in the training of elementary teachers, antiquated and unpractical methods are still prevalent, and are often greatly encouraged by examinational requirements.

\section{RADIOGRAPHY IN PEARL FISHING.}

$T H E$ products of the sea are commonly wasted to a very deplorable degree by those who gather and use them. In no instance is this waste more marked than in the search for pearls. By the old method, which is still in vogue as a general rule, an enormous number of the so-called oysters are taken from their habitat and destroyed without any thought of economy. It is said that only one pearl is found in 100 oysters, and only I per cent. of the pearls found are of any commercial value. Thus some 10,000 of the precious molluscs are sacrificed for every useful pearl obtained. Among these victims there must be a vast amount of immature pearls or seed, pearls in posse, which might grow and become valuable gems, which are deprived of that possibility by premature destruction.

In the year I901 Prof. Raphaël Dubois took radiographs of pearls in situ within the shell of Unio prolifera, and obtained a clear view of their size and situation in spite of the thickness of the shell in which they were encased. $\mathrm{He}$ showed these radiographs at the Linnean Society of Lyons, and remarked that the X-rays might receive a novel application if used in the fisheries of Ceylon, and the destruction of a vast number of the prized molluscs might thus be avoided.

The difficulty of applying the $\mathrm{X}$-rays to many thousands of shells per diem seemed sufficient to deter the ordinary person from such a laborious attempt. However, a few years later an electrical engineer of New York, Mr. John J. Solomon, who took an interest in the question of pearls, was struck by the same idea of using the X-rays to detect the existence of pearls within the shell of the living animal. He was then unaware of the earlier experiments of Prof. Dubois, but promptly set himself about the work from a commercial point of view.

$\mathrm{He}$ found that an exposure necessary to obtain a good picture did not in any way injure the animal, and even an exposure of ten times as long could be applied without causing its death from the effect of the rays. The dangers lay rather in the removal of the bivalve from its normal attachment and in the time required for its transit from its bed to the laboratory of the photographer: for the pearl oyster is really a kind of mussel, which holds on to some fixed object by a brush of fibrils (byssus) growing from its body

Thus the fundamental principle of Prof. Dubois, to save the life of unremunerative bivalves, bids fair to be carried out by American ingenuity and capital.

For practical purposes, where many thousands of shells have to be radiographed daily, a completely novel kind of plant had to be devised. This was done, and final success was considered to be well in view, when roo clear radiographs could be taken on an average every fifteen seconds. 